\title{
Experimental investigation of interaction effects in foam-filled thin-walled aluminum tubes
}

\author{
M. Güden · A. K. Toksoy • H. Kavi
}

Received: 5 August 2004 / Accepted: 7 July 2005/ Published online: 19 August 2006

(C) Springer Science+Business Media, LLC 2006

\begin{abstract}
The interaction coefficients of polystyrene foam filling of thin-walled aluminum cylindrical tubes were investigated experimentally through compression testing of partially foam-filled tubes with and without adhesive. The experimental load-displacement curves and observation of the crushed sections of filled tubes have shown that partial foam filling reduced the fold length and hence increased the average crushing loads of tubes, proving the interaction effect between tube wall and filler. The interaction coefficients for the partial foam filling were further calculated to be in the level and/or higher than that of the foam plateau load of transverse direction.
\end{abstract}

\section{Introduction}

The filling of tubular structures with light-weight foam cores in order for increasing specific energy absorption (SEA) has taken considerable scientific interest. The earliest investigations on the crushing behavior of foam-filled thin-walled sections were conducted by Thornton [1], Lampinen and Jeryan [2], Reid et al. [3] and Reddy and Wall [4]. Recent studies on aluminum (Al) foam-filled thin-walled aluminum and steel tubes

M. Güden · A. K. Toksoy · H. Kavi

Department of Mechanical Engineering, Izmir Institute of Technology, Gülbahçe Köyü, Urla, Izmir 35430, Turkey

M. Güden ( $\square)$

Center for Materials Research, Izmir Institute

of Technology, Gülbahçe Köyü, Urla, Izmir 35430, Turkey

e-mail: mustafaguden@iyte.edu.tr include those of Santosa et al. [5], Seitzberger et al. [6], Santosa and Wierzbicki [7], Hanssen et al. [8] and Toksoy et al. [9]. Foam filling generally increases the average crushing load of filled tube over the sum of the crushing loads of foam (alone) and tube (alone), which is known as interaction effect. The restraining effect of foam filler to the tube folding was also explained to be the major cause of the reduced fold length in filled tubes [7]. The entrance of the column wall into foam filler results in shorter fold lengths and increased number of folds formed [7]. Santosa et al. [5] pointed out that the encroachment of the column wall into the $\mathrm{Al}$ foam filler allows an additional compression in the foam and retards the sectional collapse of the column. Foam filling was also shown to increase the tendency for axisymmetric (concertina) mode of deformation [3]. The shift in the collapse mode from diamond into concertina with foam filling was observed in $\mathrm{Al}$ foamfilled $\mathrm{Al}$ and steel tubes, polyurethane foam-filled $\mathrm{Al}$ tubes and wood sawdust-filled plastic tubes $[5,6,10,11]$ and proposed to be due to the thickening effect of foam filling. It was further shown by Hanssen et al. [8] that after a critical $\mathrm{Al}$ foam density the deformation mode in filled $\mathrm{Al}$ tubes shifted from diamond to concertina mode. A similar mode-shift was also found in polyurethane foam-filled thin-walled $\mathrm{Al}$ tubes with the increasing foam density [10]. Santosa and Wierzbicki [7] showed that the effect of filler on the tube crushing load was similar when the strong axis of the honeycomb through and normal to the compression axis, proving that both axial and lateral strength of the filler were effective in increasing the crushing load of the tube. Further, Santosa et al. [5] noted that the bonding between filler and tube wall increased the average crushing load of filled tube over the unbounded filled 
tube when appropriate tube geometry and foam density were chosen.

Hannsen et al. $[8,12]$ developed an equation for the average crushing load of foam-filled $\left(P_{\mathrm{af}}\right)$ columns by including contributions of the average crushing load of empty tube $\left(P_{\mathrm{ae}}\right)$, foam plateau stress $\left(\sigma_{\mathrm{pl}}\right)$ and interaction effect. The equation was found to be well agreed with experimental results and is given as

$P_{\mathrm{af}}=P_{\mathrm{ae}}+\sigma_{\mathrm{pl}} b^{2}+C_{\mathrm{avg}} \sqrt{\sigma_{\mathrm{pl}} \sigma_{y}} b t$

where $C_{\text {avg, }} \sigma_{y}, b$ and $t$ are the dimensionless constant which is directly related to the interaction effect, yield strength of the tube material and tube width and thickness, respectively. The second term of the right hand side of the Eq. 1 accounts for the axial compression of the foam and the last term for the interaction effect. If the axial compression of filler is avoided experimentally, the interaction effect between foam filler and tube wall can be determined according to Eq. 1 . In this case, the interaction load $\left(P_{\text {int }}\right)$ and interaction coefficient (I) will be

$P_{\text {int }}=P_{\mathrm{fp}}-P_{\mathrm{ae}}$

$I=\frac{P_{\text {int }}}{P_{\text {foam }}}$

where, $P_{\mathrm{fp}}$ and $P_{\text {foam }}$ are the average crushing load of foam-filled tube without the axial compression of foam filler and the foam compression load corresponding to the plateau stress, respectively. Santosa et al. [5], based on FEM results, proposed the following equation for the average crushing load of foam-filled square tubes of length $b$,

$P_{\mathrm{af}}=P_{\mathrm{ae}}+C \sigma_{\mathrm{pl}} b^{2}$

The constant $C$ in Eq. 4 is considered to be the strengthening coefficient of foam filling. The values of $C$ were shown to be 1.8 and 2.8 for the unbounded and bounded cases, respectively.

The interaction and strengthening coefficients of foam-filled tubes are usually determined by fitting the experimental results of the average crushing loads of empty and foam-filled tubes to Eqs. 1 and 4, respectively. In this study, a novel experimental method was investigated to assess experimentally the interaction effect in thin-walled $\mathrm{Al}$ circular tubes deforming in diamond mode (progressive asymmetric). Al tubes in two different tube wall thicknesses and diameters were filled partially with foam (only half of the tube is filled) so that the axial deformation of foam filler was avoided during compression testing. The interaction coefficients for two cases; filled tube deformed in (a) diamond and (b) concertina modes were determined directly from the load-displacement curves of the partially foam-filled tubes based on Eqs. 2 and 3.

\section{Materials and testing}

The filler material was a commercially available extruded closed-cell polystyrene foam sheet produced by the Izocam Company of Turkey with a mean density of. $32.1 \pm 2 \mathrm{~kg} \mathrm{~m}^{-3}$ determined by dividing the mass of $5 \mathrm{~cm}$ long cubic foam sample by its volume. The cells of foam are preferentially elongated through the thickness or rise direction of as-received foam sheets. This gives rise to anisotropy in compression behavior between normal to rise (R), width (W) and extrusion (E)-directions (Fig. 1). The plateau stresses of foams normal to the R, W and E-directions were determined by the compression testing of $5 \mathrm{~cm}$ cubic foam samples.

Al (99.7\%) drawn tubes, $16 \mathrm{~mm}$ (0.22 mm thick) and $25 \mathrm{~mm}$ ( $0.29 \mathrm{~mm}$ thick) in outer diameters, were provided by the Metalum Company of Turkey. The average yield and ultimate tensile strength values of tube material were determined by the tensile testing of non-standard small size samples cut axially through drawing direction of the tubes and were found to be 112 and $170 \mathrm{MPa}$, respectively.

Three groups of compression tests were applied. The first and second groups of tests were on the empty and foam-filled tubes with and without adhesive (Fig. 2a, b). In the last group, partially foam-filled tubes with and without adhesive were tested (Fig. 2c). The foam filling was always through the $\mathrm{R}$ direction of foam as shown in Fig. 2b, c. A commercially available foam polystyrene adhesive Bison Styrabond ${ }^{\circledR}$ was used for the bonding of foam-filler to the tube wall. A tube

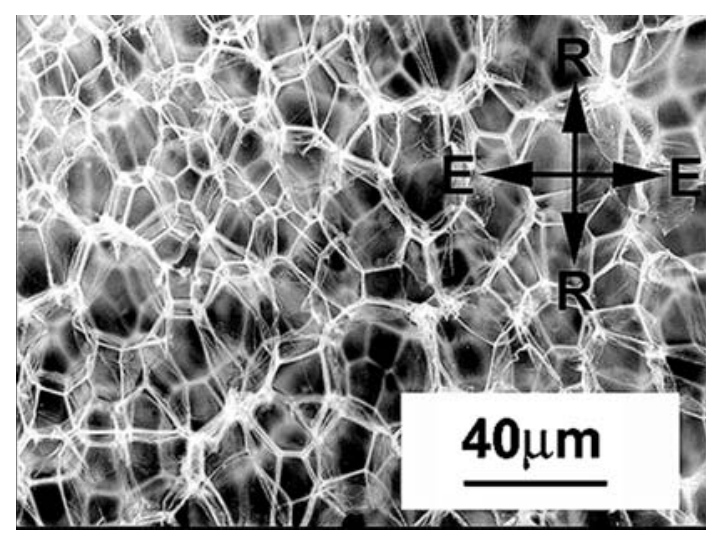

Fig. 1 The cell morphology through the rise and the extrusion direction of the foam 


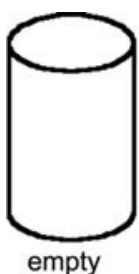

(a)

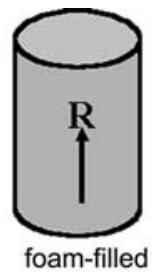

(b)

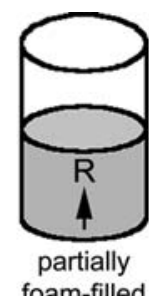

(c)
Fig. 2 Schematic of three groups of the compression tests applied to (a) empty, (b) foam-filled and (c) partially foam-filled tubes

length to diameter ratio of 1.6 , which avoided tube global buckling, was used in all tests.

Compression tests were conducted using a displacement controlled Schimadzu AG-I universal test machine. Empty and foam-filled tubes were compressed at a cross-head speed of $2.5 \mathrm{~mm} \mathrm{~min}{ }^{-1}$ with a corresponding deformation rate of $1 \times 10^{-3} \mathrm{~s}^{-1}$. The average crushing load of empty and filled tubes are calculated using the following relations,

$P_{\mathrm{ae}}(\delta)=\frac{\int_{0}^{\delta} P \mathrm{~d} \delta}{\delta}$

where $P$ and $\delta$ are the load and displacement, respectively. The weights of tubes were measured before and after filling, hence the weight of adhesive used was calculated. The amount of adhesive used varied between 3 and $6 \%$ of the total weight of filled tube.

\section{Results and discussions}

Figure 3 shows the compression nominal stress-strain curves of the foam tested normal to the R, W and Edirections. Anisotropy in compression behavior is clearly seen in this figure; foam shows a higher plateau stress in the R-direction. As shown in Fig. 3, foam stress in the plateau region is nearly constant until about 0.4 and 0.2 strains for $\mathrm{R}$ and $\mathrm{W}$-directions, respectively.

Empty tubes deformed in diamond mode with 6 and 8 corners per fold and totally 9-10 and 7-8 folds formed in 16 and $25 \mathrm{~mm}$ empty tubes, respectively. It is also noted that folding in both tubes started in axisymmetric mode before reverting into diamond mode, a phenomenon observed in multi-mode collapse mode [13].

Similar to empty tubes, foam-filled $16 \mathrm{~mm} \mathrm{Al}$ tube collapsed in diamond mode and totally 10-12 folds formed. In partially foam-filled $16 \mathrm{~mm} \mathrm{Al}$ tube with and without adhesive the deformation mode remained

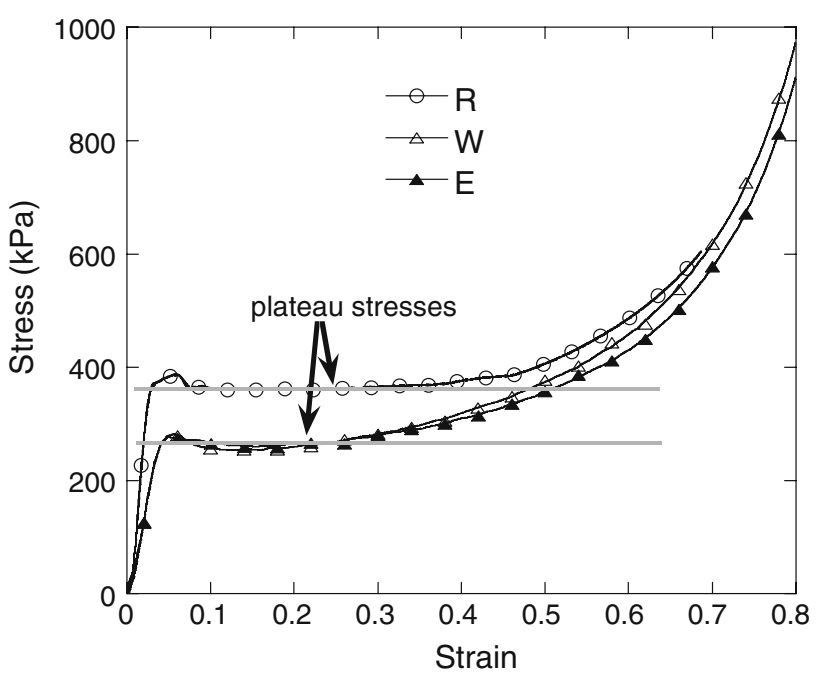

Fig. 3 Nominal compression stress-strain curves of the foam through $\mathrm{R}, \mathrm{E}$ and $\mathrm{W}$ directions

to be the same with that of empty tube (diamond), but folding started either at the filled (sample A) or nonfilled end (sample B) of the tube (Fig. 4a, b). The loaddisplacement and average crushing load -displacement curves of foam-filled, partially foam-filled sample A and empty tubes are shown in Fig. 5(a, b), respectively. The partial foam filling of samples A increases the load and average crushing load values and decreases the fold length (Fig. 5a, b). It is also noted that the loaddisplacement pattern and fold length of partially foamfilled tube are very similar to those of foam-filled tube except the load values are lower in partially filled tube (Fig. 5a). The average crushing load of partially foamfilled tube is slightly higher than that of foam (R)+empty tube (foam alone + tube alone) while

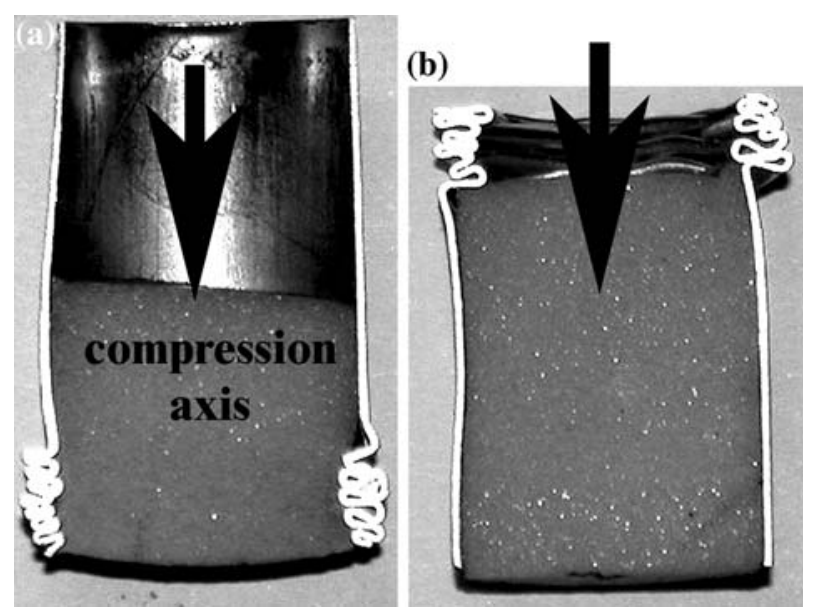

Fig. 4 Compressed sections of partially foam-filled $16 \mathrm{~mm}$ tube, folding starts (a) at the filled end (sample A) and (b) at the nonfilled end (sample B) 

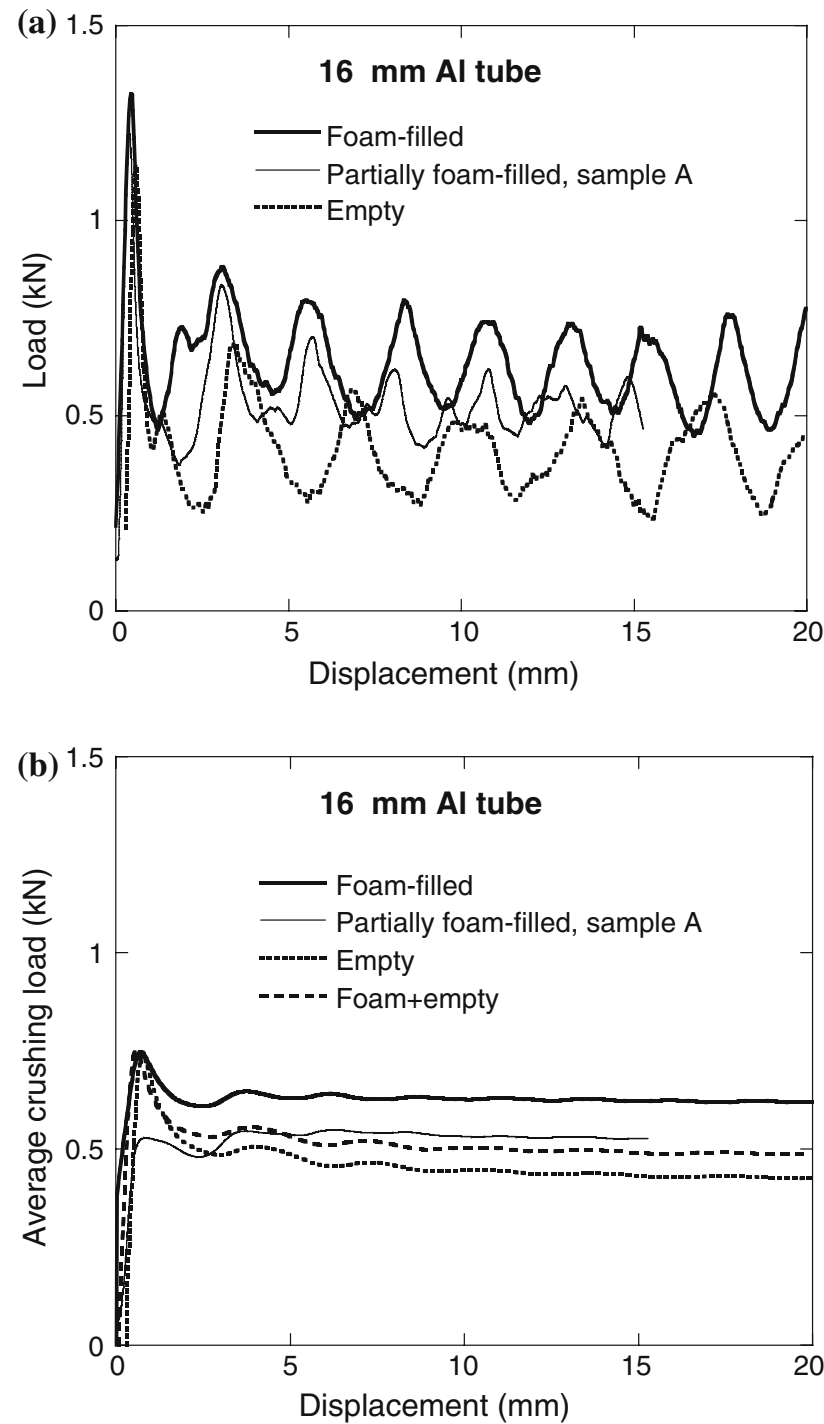

Fig. 5 (a) Load displacement and (b) average crushing loaddisplacement curves of empty, partially filled (sample A) and filled $16 \mathrm{~mm}$ tube with adhesive

lower than that of filled tube. In samples B of partially foam-filled $16 \mathrm{~mm}$ tubes, the fold length and the load values are more or less similar to those of empty tube until the point a of Fig. 6(a), at which folding starts to proceed in the foam-filled section, thereafter, due to the axial compression of the filler the load values increase and the fold length decreases to the level of filled tube. The average crushing load of partially foam-filled sample B is also noted to be slightly higher than that of empty tube (Fig. 6b). In partially foamfilled $16 \mathrm{~mm}$ tubes without adhesive the load-displacement curves are also found to be very similar to those of filled tubes with adhesive.

In the partial filled $25 \mathrm{~mm}$ tubes with and without adhesive, similar to $16 \mathrm{~mm}$ tubes, folding started either at the filled (sample A) or at the non-filled
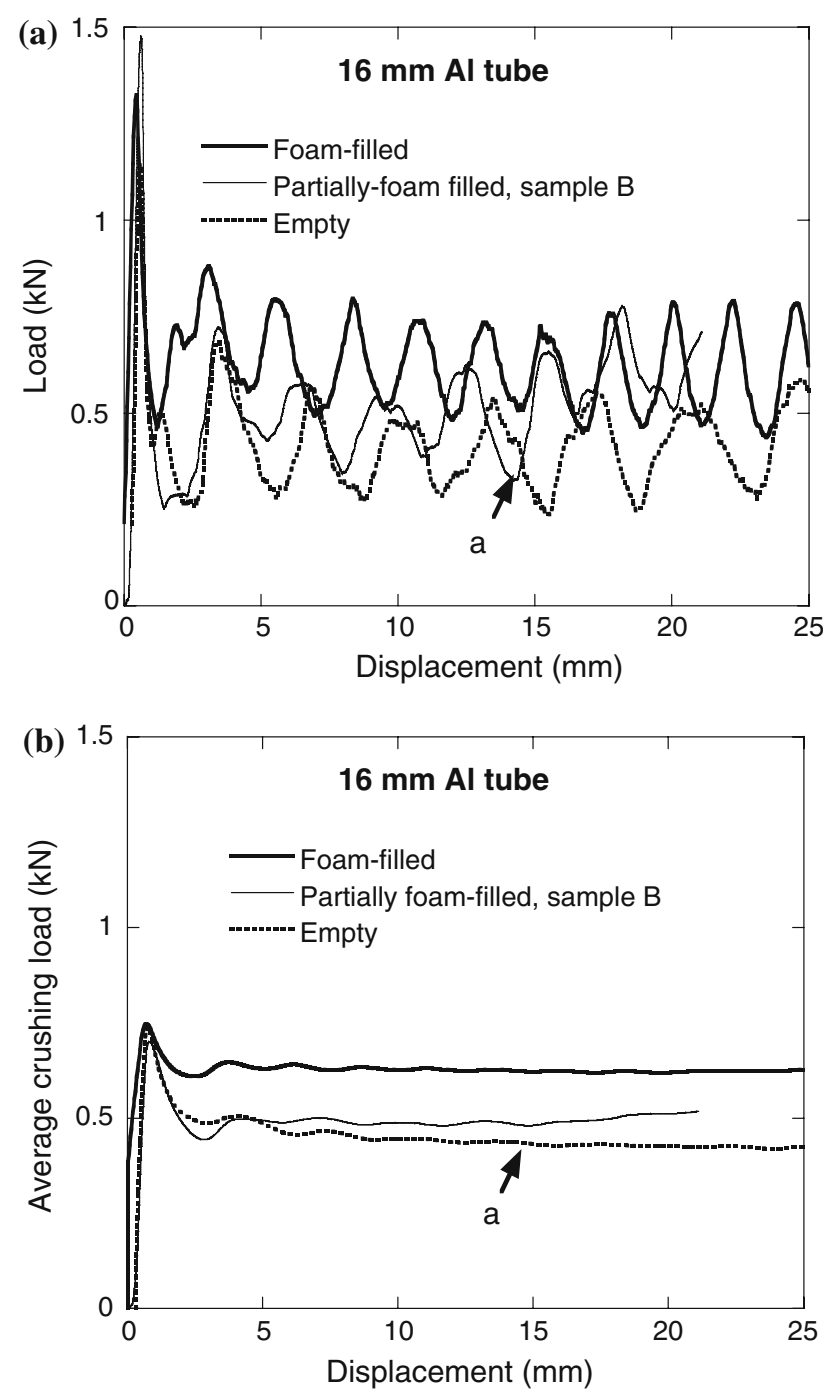

Fig. 6 (a) Load displacement and (b) average crushing loaddisplacement curves of empty, partially filled (sample B) and filled $16 \mathrm{~mm}$ tube with adhesive

(sample B) end (Fig. 7a, b). The use of adhesive in samples A however shifted the deformation mode from diamond into concertina (Fig. 7c) while empty and partailly foam-filled without adhesive tubes deformed into diamond mode. The load-displacement and average crushing load-displacement curves of $25 \mathrm{~mm} \mathrm{Al} \mathrm{empty} \mathrm{and} \mathrm{foam-filled} \mathrm{and} \mathrm{partially} \mathrm{foam-}$ filled (sample A) tubes without adhesive are shown in Fig. 8(a, b) respectively. The effect of foam filling in samples A without adhesive, is the reduction of the fold length and increase of the average crushing load values over the empty tubes to a level of foam (R)+empty tube (Fig. 8b). The load-displacement characteristic and fold length of samples A of partially foam-filled tube with adhesive are very similar to that of foam-filled tube except the average load 
Fig. 7 Crushed cross-sections of partially foam-filled $25 \mathrm{~mm}$ tube, folding starts (a) at the filled end (sample A) and (b) at the non-filled end (sample B) of without adhesive and (c) sample A with adhesive
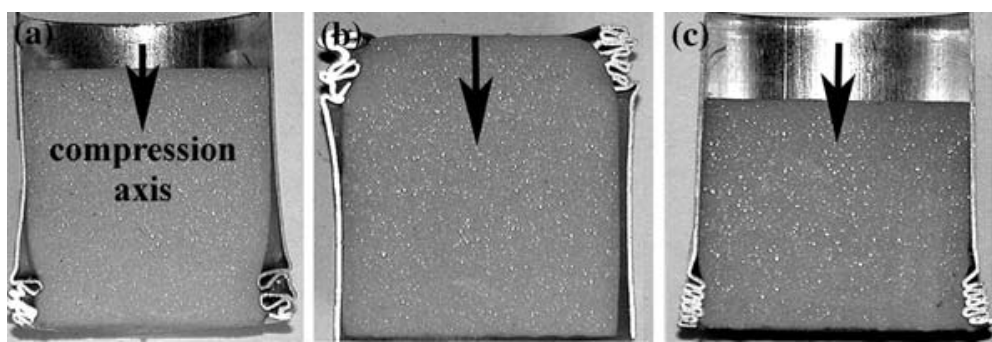

values are lower in partially filled tube (Fig. 9a, b). The average crushing load of partially foam-filled tube in these samples is higher than that of foam (R)+empty tube (Fig. 9b). In patially foam-filled
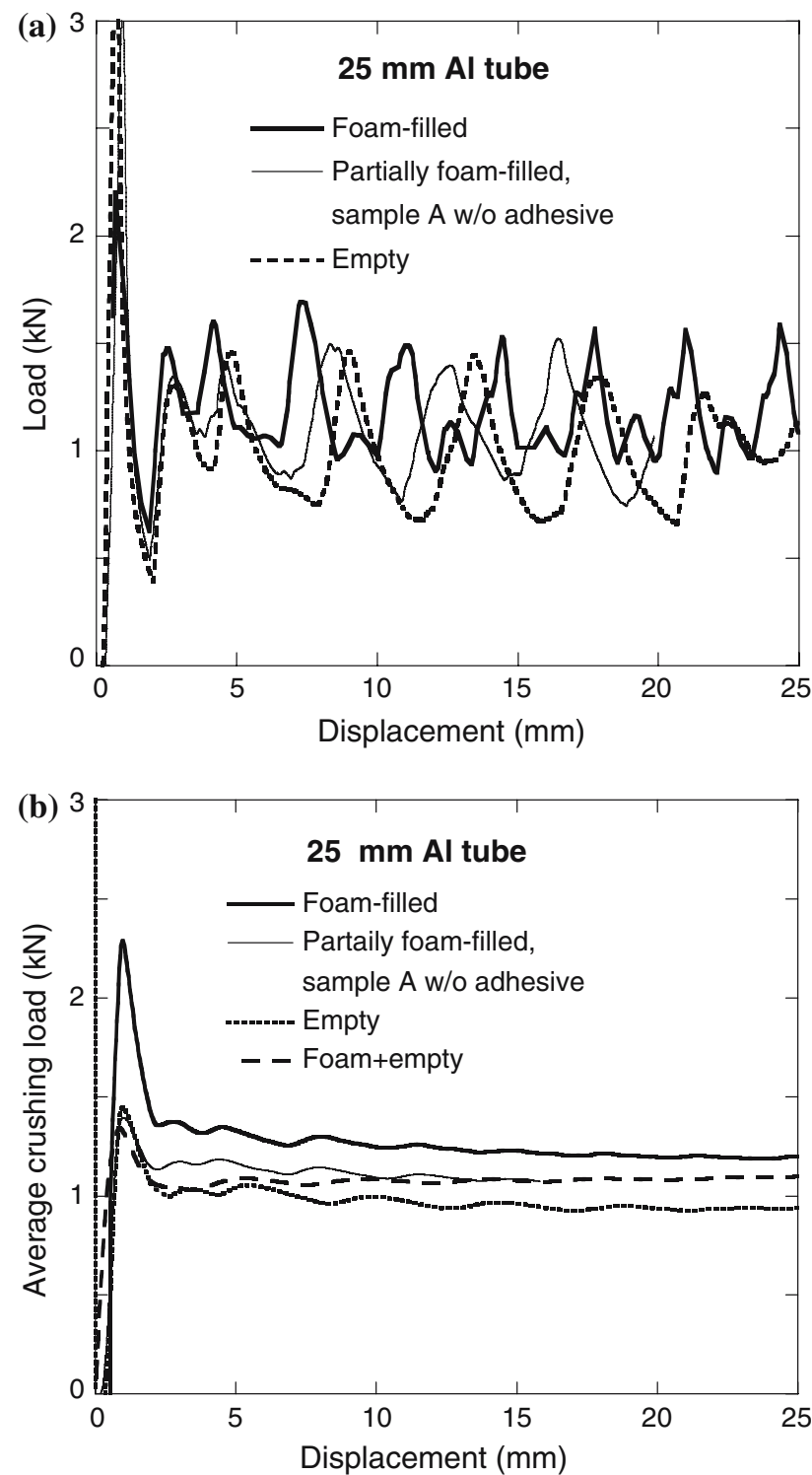

Fig. 8 (a) Load displacement and (b) average crushing loaddisplacement curves of empty, partially filled (sample A) and filled $25 \mathrm{~mm}$ tube without adhesive
$25 \mathrm{~mm}$ tube of samples $\mathrm{B}$, the fold length and load values are however the same with those of empty tubes until the point a of Fig. 10, at which folding starts to proceed in the filled section. Thereafter, load
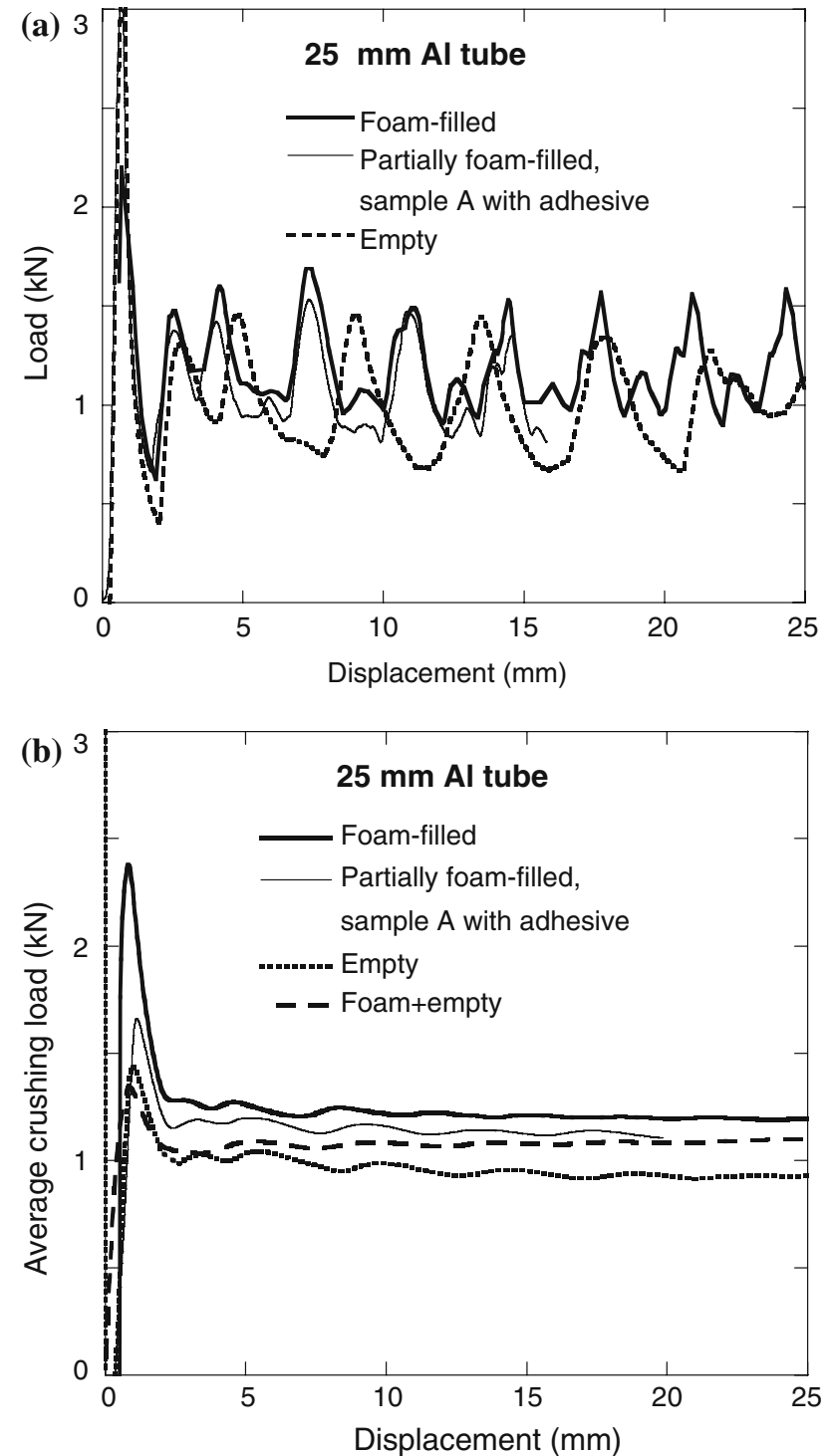

Fig. 9 (a) Load displacement and (b) average crushing loaddisplacement curves of empty, partially filled (sample A) and filled $25 \mathrm{~mm}$ tube with adhesive 


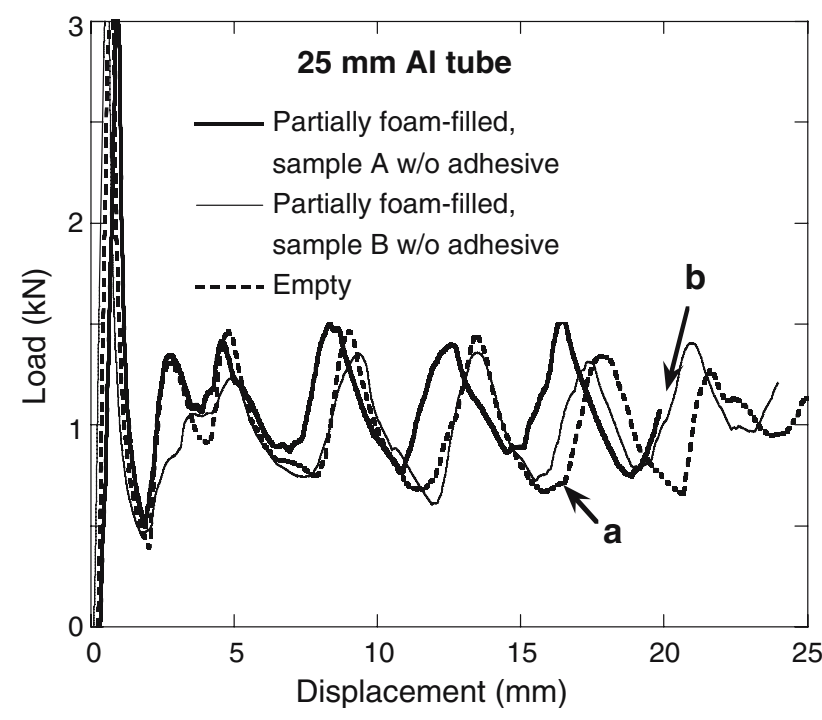

Fig. 10 Load displacement curves partially foam-filled sample with and without adhesive (sample B) and empty tubes of $25 \mathrm{~mm}$ tube

values increase to those of sample A without adhesive (point b) in Fig. 10.

It was noted the triggering position of folding in partially filled tubes was random and might be affected by the geometrical parameters of foam-filled tube and the constraints imposed by the compression test plates. Tests were conducted until about at least 3 consistent load-displacement curves obtained for each configuration and sample type. Figure 11 shows the average crushing loads of filled, partially foam-filled and empty tubes as well as the variations in the average crushing loads between 3 tests conducted at the same configuration. For comparison, the load-displacement curves

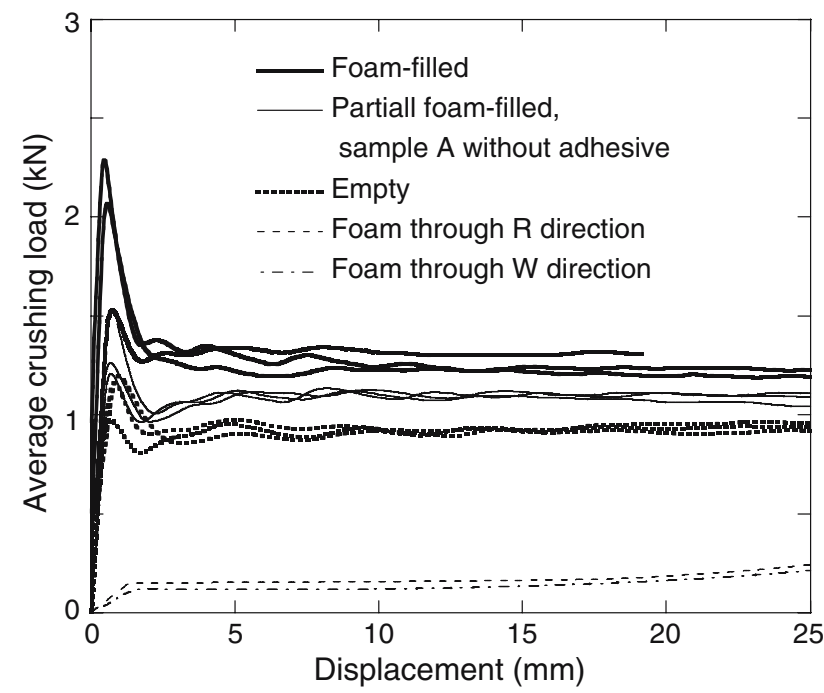

Fig. 11 Average crushing loads of filled, partially foam-filled and empty $25 \mathrm{~mm}$ tubes

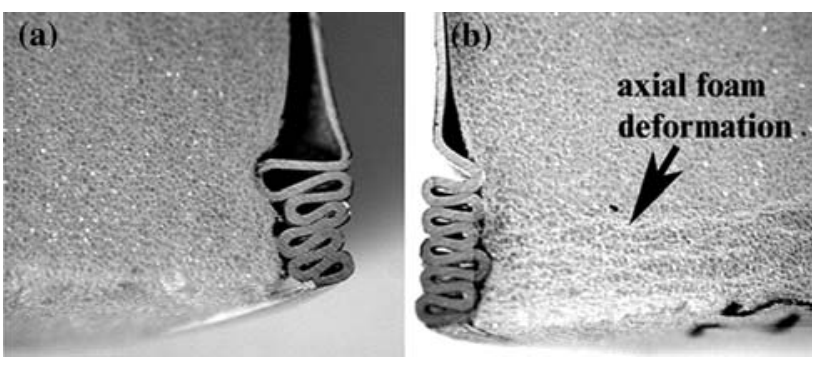

Fig. 12 Crushed cross-sections of partially foam-filled $25 \mathrm{~mm}$ tubes (a) without adhesive and (b) with adhesive

of the foam in $\mathrm{R}$ and $\mathrm{W}$ directions are also shown in the same figure.

The important deformation parameters of empty, partially foam-filled and foam-filled 16 and $25 \mathrm{~mm} \mathrm{Al}$ tubes are tabulated in Tables 1 and 2, respectively. In these tables, $\Delta \mathrm{P}_{\mathrm{a}}$ refers to the increase in average crushing load of tubes with foam filling. The relatively high values of initial peak loads were effective in increasing average crushing loads, particularly at low displacements. The average crushing loads were also calculated by simply changing the integration limits in Eq. 5 and found that the difference between the average crushing loads with and without excluding initial peak loads diminished with increasing displacement and became negligible ( $3 \%$ difference) at $15 \mathrm{~mm}$ displacement. The average crushing load values were therefore calculated at $15 \mathrm{~mm}$ displacement. The effect of partial foam filling on the crushing behavior of tested Al tubes can be also noted in Tables 1 and 2; the fold lengths reduced and average crushing loads increased. It is also noted in Table 1 that the fold lengths of partially foam-filled and foam-filled $16 \mathrm{~mm} \mathrm{Al}$ tubes are very similar. A similar behavior is also found in partially foam-filled with adhesive and foam-filled $25 \mathrm{~mm} \mathrm{Al}$ tubes (Table 2). The interaction coefficients listed in Tables 1 and 2 were calculated based on the foam plateau load through $\mathrm{R}$ and transverse directions. The first numbers in these tables show the calculations based on through $\mathrm{R}$ direction foam plateau load and the second based on the transverse to R-direction plateau load. The calculations based on foam plateau load in the R-direction give the interaction coefficients of 1.47 for $16 \mathrm{~mm}$ partially filled tubes and 0.96 and 1.14 for $25 \mathrm{~mm}$ partially filled tubes without and with adhesive, respectively. Based on foam transverse plateau load, the interaction coefficients for $16 \mathrm{~mm}$ partially filled is 1.7 , for $25 \mathrm{~mm}$ partially filled with adhesive is 1.3 and for $25 \mathrm{~mm}$ partially filled with adhesive is 1.1 , about unity.

The increase in the average crushing loads of partially foam-filled tube (without adhesive) with respect 
Table 1 Crushing parameters of empty, partially foam-filled and foam-filled $16 \mathrm{~mm} \mathrm{Al} \mathrm{tubes} \mathrm{(average} \mathrm{of} \mathrm{at} \mathrm{least} 3$ tests)

\begin{tabular}{llllll}
\hline Material & $P_{\mathrm{a}}(\mathrm{kN})$ & $\begin{array}{l}\Delta P_{\mathrm{a}}\left(P_{\mathrm{af}}-P_{\mathrm{ae}}\right) \\
(\mathrm{kN})\end{array}$ & $\begin{array}{l}\text { Number } \\
\text { of folds }\end{array}$ & $\begin{array}{l}\text { Fold Length } \\
(\mathrm{mm})\end{array}$ & $\begin{array}{l}\text { Interaction } \\
\text { Coefficient (I) }\end{array}$ \\
\hline Empty & 0.43 & 0 & $9-10$ & $3.4-3.8$ & Def. Mode \\
Partially filled (adhesive) & 0.53 & 0.1 & & $2.2-2.3$ & $1.4-1.7$ \\
Filled & 0.63 & 0.2 & $10-11$ & $2.2-2.5$ & diamond \\
\hline
\end{tabular}

Table 2 Crushing parameters of empty, partially foam-filled and foam-filled $25 \mathrm{~mm} \mathrm{Al}$ tubes (average of a least 3 tests)

\begin{tabular}{|c|c|c|c|c|c|c|}
\hline Material & $P_{\mathrm{a}}(\mathrm{kN})$ & $\begin{array}{l}\Delta P_{\mathrm{a}}\left(P_{\mathrm{af}}-P_{\mathrm{ae}}\right) \\
(\mathrm{kN})\end{array}$ & $\begin{array}{l}\text { Number } \\
\text { of folds }\end{array}$ & $\begin{array}{l}\text { Fold Length } \\
(\mathrm{mm})\end{array}$ & $\begin{array}{l}\text { Interaction } \\
\text { Coefficient (I) }\end{array}$ & Def. Mode \\
\hline Empty & 0.94 & 0 & $7-8$ & $4.1-4.5$ & & diamond \\
\hline Partially filled & 1.1 & 0.16 & & $3.9-4$ & $0.96-1.1$ & diamond \\
\hline Partially filled (adhesive) & 1.13 & 0.19 & & $3.2-3.5$ & $1.14-1.3$ & concertina \\
\hline Filled & 1.23 & 0.29 & $9-10$ & $3.2-3.5$ & & concertina \\
\hline
\end{tabular}

Fig. 13 Crushed crosssections of partially foamfilled $16 \mathrm{~mm}$ tubes (a) without adhesive and (b) with adhesive

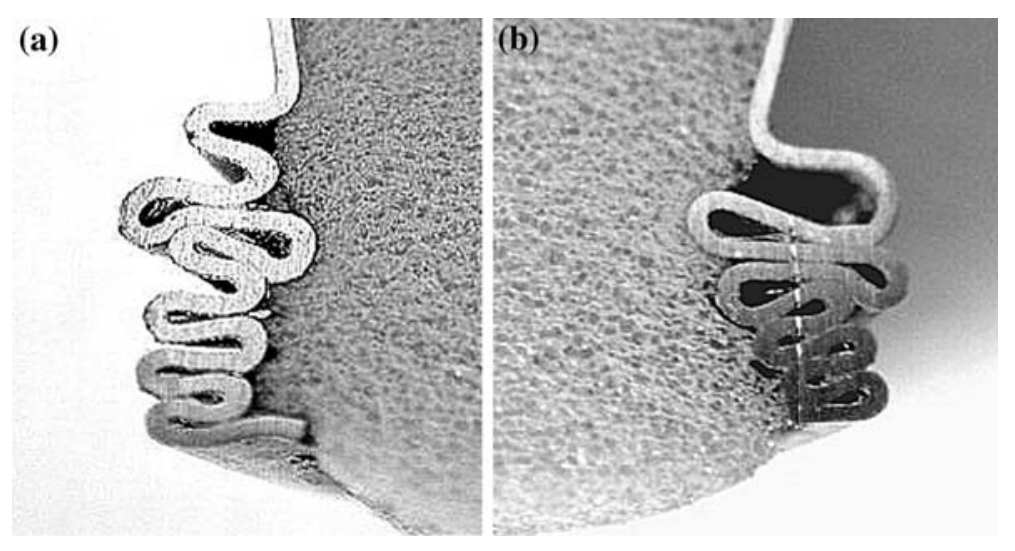

to the empty tube is mainly due to the resistance of foam filler to the inward folding of the thin-walled tube, leading to shorter fold lengths and hence increased crushing loads. The interaction effect, which was previously shown to be in the level of the foam strength for the square tubes [7], was in accord with the partially filled $25 \mathrm{~mm}$ without adhesive. In $16 \mathrm{~mm}$ and $25 \mathrm{~mm}$ with adhesive $\mathrm{Al}$ tubes the interaction coefficient is however higher than the foam transverse plateau load (1.7 and 1.3). A close inspection of the crosssection of the partially deformed $25 \mathrm{~mm}$ without adhesive tubes showed only lateral contraction of the filler (Fig 12a) while in $25 \mathrm{~mm}$ with adhesive tube besides lateral contraction the axial deformation of the filler was observed (Fig 12b). A similar effect, deformation in the axial direction of filler was also observed in $16 \mathrm{~mm}$ partially filled with and without adhesive tubes as shown in Fig. 13(a,b). These results tended to confirm an interaction coefficient higher than filler plateau load in the case of axial deformation of the filler. One of the reasons for the observed axial deformation of the filler might be the filler entrance in between the folds, leading to a higher strengthening than the transverse filler load.

In the filled tubes, the interaction effect may be partly due to the resistance of filler to the inward and/ or outward folding of tube wall and partly due to the interfacial friction stress between foam and tube wall. Numerical studies of $\mathrm{Al}$ foam-filled tubes have shown a negligible effect of interfacial frictional stress on the crushing strength of tubes [5]. The use of adhesive can contribute to the specific energy absorption of tube by two mechanisms, namely, increased load transfer from tube wall to the foam core and peeling of the adhesive. The latter mechanism occurs mainly due to the outward folding of the tube. In the partially filled $25 \mathrm{~mm}$ Al tube with adhesive, the filler remained to be attached to the tube wall throughout the crushing process. This is likely to result in higher load transfer to the foam filler and change of deformation mode.

The present results on the partially foam-filled thinwalled $\mathrm{Al}$ tubes have shown few effects of the filler on the crushing behavior of thin walled tubes. In the absence of axial compression of foam filler, the resis- 
tance to tube folding provided by the filler is about in the level of filler lateral load. The resistance of foam filler in partially filled tubes reduces the fold length in the level of the filled tubes. However, the results should be taken cautiously since the axial deformation of the filler may results in changes in the lateral resistance of filler to the tube folding in filled tubes.

\section{Conclusions}

The interaction coefficients of polystyrene foam filling of thin-walled aluminum cylindrical tubes, $16 \mathrm{~mm}$ and $25 \mathrm{~mm}$ in diameter, were investigated experimentally through compression testing of partially foam-filled tubes with and without adhesive. In partially foam-filled $16 \mathrm{~mm}$ tube the deformation mode was the same with those of empty and filled tube. In partially filled $25 \mathrm{~mm}$ tubes without adhesive the deformation mode was diamond while the use of adhesive reverted the deformation mode in the partially filled tube into concertina, which the same with that of filled tube. The effect of partial foam filling was to reduce the fold length and increase the average crushing loads of tubes. The interaction coefficients for the partial foam filling were further shown to be in the level and/or higher than that of the foam plateau loads.

\section{References}

1. Thornton PH (1980) Energy absorptions by foam-filled structures. SAE paper 800372

2. Lampinen BH, Jeryan RA (1982) Effectiveness of polyurethane foam in energy absorbing structures. SAE paper 820494

3. Reid SR, Reddy TY, Gray MD (1986) Int J Mech Sci 23:295

4. Reddy TY, Wall RJ (1988) Int J Impact Eng 7:151

5. Santosa S, Wierzbicki T, Hanssen AG, Langseth M (2000) Int J Impact Eng 24:509

6. Seitzberger M, Rammerstorfer FG, Gradinger R, Degischer HP, Blaimschein M, Walch C (2000) Int J Solids Struct 37:4125

7. Santosa S, Wierzbicki T (1998) Comput Stuct 68:343

8. Hannsen AG, Langseth M, Hopperstad OP (2000) Int J Impact Eng 24:475

9. Toksoy AK, Guden M, Tanoglu M, Hall IW (2004) J Mater Sci 39:1503

10. Guillow SR, Lu G, Grezbieta RH (2001) Int J Mech Sci 43:2103

11. Singace AA (2000) Thin Wall Sturct 37:163

12. Hanssen AG, Langseth M, Hopperstad OS (2000) Int J Impact Engineering 24:347

13. Singace AA (2000) IJ Crash 5:297 